Article

\title{
Evaluation Method of Production Pressure Differential in Deep Carbonate Reservoirs: A Case Study in Tarim Basin, Northwest China
}

\author{
Haoyang Weng ${ }^{1}$, Jingen Deng ${ }^{1}$, Chunfang Zhang ${ }^{1}$, Qiang Tan ${ }^{1, *}$, Zhuo Chen ${ }^{2}$ and Wei Liu ${ }^{1}$ \\ 1 Department of Petroleum Engineering, State Key Laboratory of Petroleum Resources and Exploration, \\ China University of Petroleum-Beijing, Beijing 102249, China; wenghy910@163.com (H.W.); \\ dengig@cup.edu.cn (J.D.); $2019210216 @$ student.cup.edu.cn (C.Z.); liuwei@cup.edu.cn (W.L.) \\ 2 Tianjin Branch of CNOOC (China) Co., Ltd., Tianjin 300459, China; chenzhuo8@cnooc.com.cn \\ * Correspondence: tanqiang_cup@126.com
}

Citation: Weng, H.; Deng, J.; Zhang, C.; Tan, Q.; Chen, Z.; Liu, W.

Evaluation Method of Production

Pressure Differential in Deep

Carbonate Reservoirs: A Case Study

in Tarim Basin, Northwest China.

Energies 2021, 14, 2721. https://

doi.org/10.3390/en14092721

Academic Editor: Yosoon Choi

Received: 16 April 2021

Accepted: 5 May 2021

Published: 10 May 2021

Publisher's Note: MDPI stays neutral with regard to jurisdictional claims in published maps and institutional affiliations.

Copyright: (C) 2021 by the authors Licensee MDPI, Basel, Switzerland. This article is an open access article distributed under the terms and conditions of the Creative Commons Attribution (CC BY) license (https:// creativecommons.org/licenses/by/ $4.0 /)$.

\begin{abstract}
Deep and even ultra-deep petroleum resources play a gradually increasing and important role with the worldwide continuous advancement of oil and gas exploration and development. In China, the deep carbonate reservoirs in the Tarim Basin are regarded as the key development areas due to their huge reserves. However, due to the unreasonable design of production pressure differential, some production wells suffered from severe borehole collapse and tubing blockage. Therefore, the main purpose of this paper is to optimize a more practical method for predicting the critical production pressure differential. The commonly used analytical methods with different failure criteria for predicting production pressure differential were summarized. Furthermore, their advantages and disadvantages were analyzed. A new numerical model is established based on the finite element theory in order to make the prediction of production pressure differential more accurate. Additionally, both analytical and numerical methods were applied to evaluating the production pressure differential of deep carbonate reservoirs in the Tarim Basin, and the results were discussed compared with field data. In addition, a series of laboratory tests, including porosity and permeability measurements, electron microscope scanning, XRD for mineral analysis, uniaxial and triaxial compressive strength test, etc., were carried out by using the collected carbonate cores from formations deeper than $7000 \mathrm{~m}$ to obtain the input parameters of the simulation such as the rock properties. The experimental results showed that the carbonate rocks exhibited a remarkable brittleness and post-peak strain softening. The calculation results revealed that the Mogi-Coulomb criterion is slightly conservative; however, it is more suitable than other criteria to evaluate pressure differential. Furthermore, it has been confirmed by the field data that the finite element numerical method can not only reveal the instability mechanism of the wellbore but also predict the critical production pressure differential accurately. Unfortunately, the on-site operators sometimes require a more convenient way, such as an analytical method, to figure out the pressure differential, even though the evaluation of the numerical method is more accurate. Therefore, the discussion in this paper can provide a basis for the operators to determine the production pressure differential flexibly.
\end{abstract}

Keywords: carbonate reservoir; production pressure differential; laboratory test; failure criterion; finite element; strain softening

\section{Introduction}

The exploration and development of petroleum resources are in full swing nowadays due to the increasingly prominent contradiction between petroleum supply and demand with the continued growth in global demand for fossil energy. Moreover, $60 \%$ of global oil and gas reserves are derived from carbonate reservoirs, which occupy an important position in the world's total petroleum resources [1]. In China, more than one-third of the reserve resources are the oil and gas in the marine carbonate rocks, and thus carbonate 
reservoirs have become one of the most important strategic replacement resources [2]. There is a large number of carbonate reservoirs with huge productivity in the Tarim Basin that has become a key area for deep petroleum development $[3,4]$.

Carbonate reservoir space can be divided into three types: primary pores, fractures and caves. It is common knowledge that the complexity of physical properties often leads to the complexity of rock strength [5]. Therefore, some of the production wells in the Tarim Basin encountered wellbore collapse and tubing blockage (Figures 1 and 2) during drilling due to the insufficient understanding of the complex rock properties and the excessive highly designed pressure differential, which caused a lot of economic losses and non-productive time. So, it is of great significance to thoroughly carry out research on the critical production pressure differential of carbonate reservoirs in the Tarim Basin.

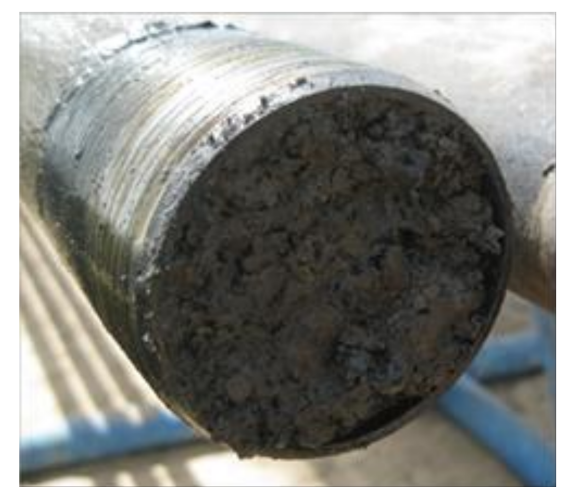

Figure 1. Sectional view of blocked tubing.

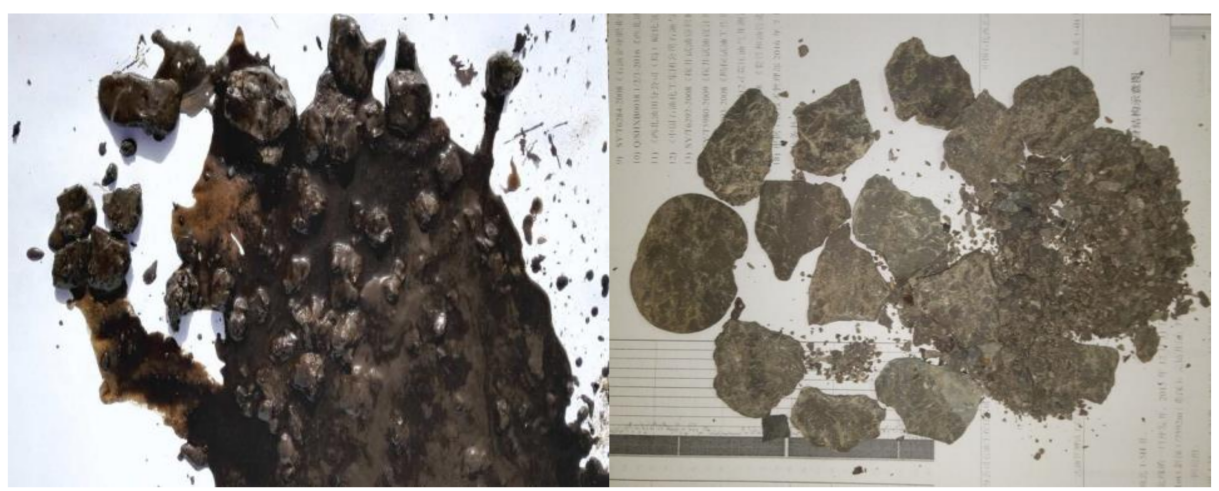

Figure 2. The mixture of mud and clogging cuttings (left), the block falling (right).

Domestic and foreign scholars have developed many methods on the critical production pressure differential prediction [6-14], which are mainly applied to solving the problems of sand production and wellbore instability of loose sandstone and tight sandstone. In 2007, Liu X. et al. [10] believed that the elastoplastic model could better reflect the mechanical properties of sandstone reservoirs. They calculated the distribution of the equivalent plastic strain around the wellbore and determined the production pressure differential considering the plastic strain criterion. In 2011, Wang A. [11] demonstrated that the initial sanding did not occur on the borehole wall but in the stratum. Therefore, a concept of sanding characteristic radius was proposed, and the methods of critical pressure differential determination were established based on different criteria, such as Mohr-Coulomb [15], Drucker-Prager [16], Hoek-Brown [17], plastic strain [18], tensile failure [6] and compression failure [6]. In 2016, Zhang R. et al. [12] analyzed rock stresses of the borehole wall and developed a new sanding critical drawdown pressure calculating model combined with fully polyaxial rock failure criterion Mogi-Coulomb [19]. In 2019, Geng S. [13] established a finite-difference grid model by FLAC3D to simulate wellbore instability and collapse under different pressure differentials. The numerical results showed 
that the pressure differential without large-scale collapse around the wellbore was reasonable and practical. In 2020, Shi X. et al. [14] established the calculation method of the wellbore instability index under the condition of pressure depletion, which was used to characterize the risk of sand production around the wellbore. Then, the diagram between the bottom-hole flow pressure and pore pressure was drawn to determine the production pressure differential during the entire production cycle of pressure depletion.

Although the research achievements on the critical production pressure differential of sandstone reservoirs are abundant, their applicability to carbonate reservoirs in the Tarim Basin remains to be investigated. Therefore, research on the optimal evaluation methods of production pressure differential is included in this paper in order to provide a basis for well testing and production design work in the oilfield.

\section{Experimental Study on the Properties of Carbonate Rocks}

When it comes to evaluating the production pressure differential, the necessary prerequisite is to find out the stratigraphic characteristics of the target area, the most important of which is the rock properties. Rock properties are usually divided into mechanical, physical and chemical properties. Mechanical properties characterize the rock's abilities to resist deformation and failure under the stress state, and they are usually evaluated by parameters such as elastic modulus, Poisson's ratio, compressive strength, cohesion and internal friction angle. The physical properties of the rock mainly include fabric characteristics, porosity and permeability. The chemical properties mainly characterize the changes in physical and mechanical properties caused by the interaction between rocks and drilling fluids.

\subsection{Experimental Study on Rock Mechanical Properties}

The mechanical properties of carbonate rocks are very complex, which mainly manifest as strong heterogeneity. Furthermore, the difference in rock strength caused by its heterogeneity is mostly determined by the fracture system inside the rock, which has been confirmed by the research of many scholars [20-23]. As an example, Tan Q. et al. have carried out some mechanical experiments by using the carbonate cores obtained from the Tarim Basin and proposed a method based on the Hoek-Brown criterion to divide the rock strength into three groups in terms of their internal cracks [24].

The laboratory experiments carried out in this study were aimed to analyze the typical mechanical parameters, rock failure characteristics and constitutive equations. The stressstrain curves obtained from the experiments are partly shown in Figure 3, whose data was collected by the TAW-1000 deep-water pore pressure servo experimental system. The schematic representation of the experimental setup can be found in reference [25], and the experimental procedure can be found in reference [26]. It can be found that the uniaxial compressive strength of the carbonate rocks is relatively high, and the strength is greatly increased under high confining pressure, which is conducive to maintaining the stability of the wellbore. Under uniaxial conditions, the pre-peak stress-strain curve of the core basically maintains an oblique linear shape, and the axial strain corresponding to the failure strength is about $0.5-1 \%$, indicating that the compression failure of the core is an elastic and brittle failure with remarkable residual strength. The pre-peak stress features fluctuation, which is caused by local damage or local axial splitting of the core during the compression process, and that does not affect the overall strength. The stress-strain curve at the initial stage of uniaxial compression has a remarkable "upward" trend, which is mainly due to the compaction of the inside cracks. Under triaxial conditions, the core features strain-softening after the peak strength, and the residual strength is higher than that under uniaxial conditions due to the effect of confining pressure. 


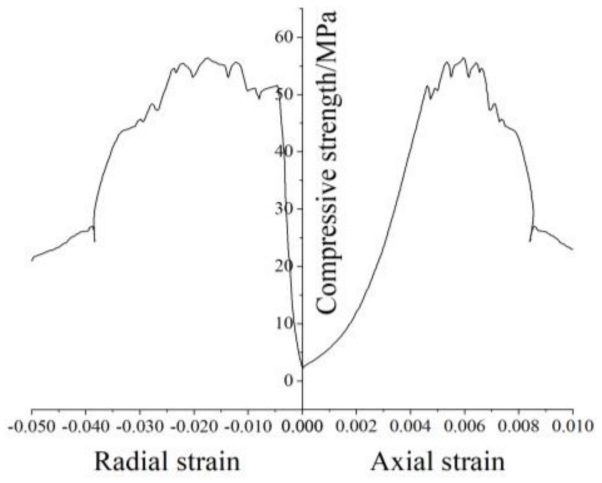

(a)

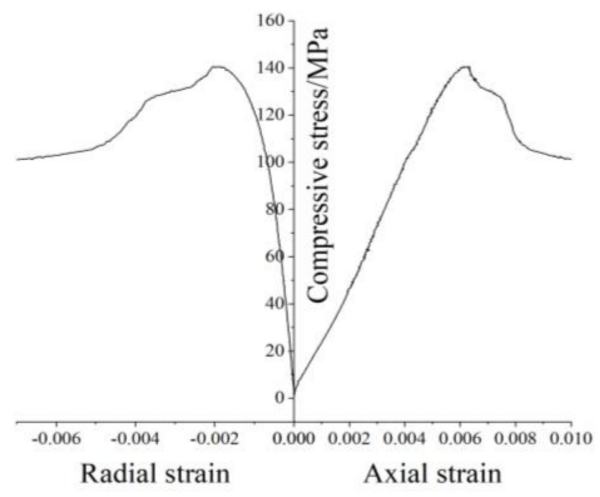

(c)

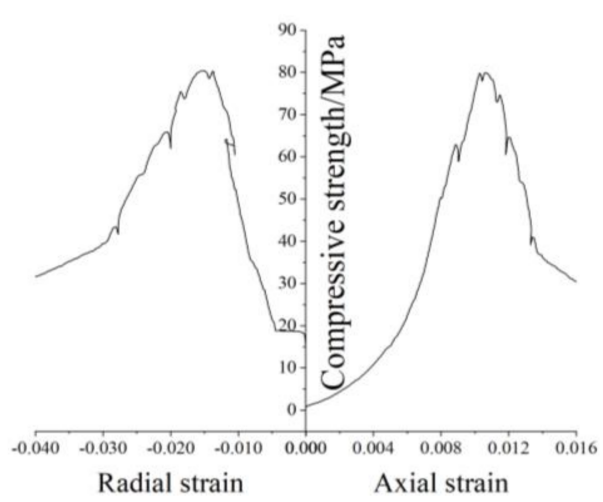

(b)

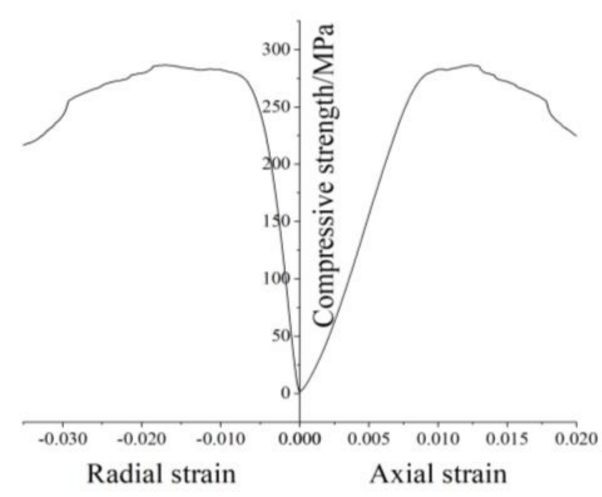

(d)

Figure 3. Stress-strain curves of carbonate strength test (the confining pressure: (a) $0 \mathrm{MPa}$; (b) $0 \mathrm{MPa}$; (c) $15 \mathrm{MPa}$; (d) $40 \mathrm{MPa}$ ).

Experimental results show that the uniaxial compressive strength (UCS) of the carbonate rocks is about $25-80 \mathrm{MPa}$ (Figure 4), which indicates a strong heterogeneity. Therefore, the wellbore stability of the weak layers must be taken into account when designing the production pressure differential. Specifically, the mechanical parameters such as strength should be determined as the statistical average values or smaller values to reduce the risk of instability. Therefore, a series of uniaxial and triaxial tests were carried out to get the range of mechanical parameters. The test conditions and results are listed in Table 1. In addition, all the rock samples are divided into several groups according to the different conditions (confining pressure) and distinguished by the frame-line in Table 1. It can be found that the average UCS of the carbonate rocks is about $47.5 \mathrm{MPa}$, the range of elastic modulus (E) is 10-20 GPa, and the range of Poisson's ratio is 0.19-0.27. By fitting the Mohr-Coulomb criterion (Equation (1)) [15], the cohesion (C) is about 11-17 MPa, and the internal friction angle $(\varphi)$ is about $42-46^{\circ}$.

$$
\sigma_{1}=\sigma_{3} \cot ^{2}\left(\frac{\pi}{4}-\frac{\varphi}{2}\right)+2 C \cot \left(\frac{\pi}{4}-\frac{\varphi}{2}\right)
$$




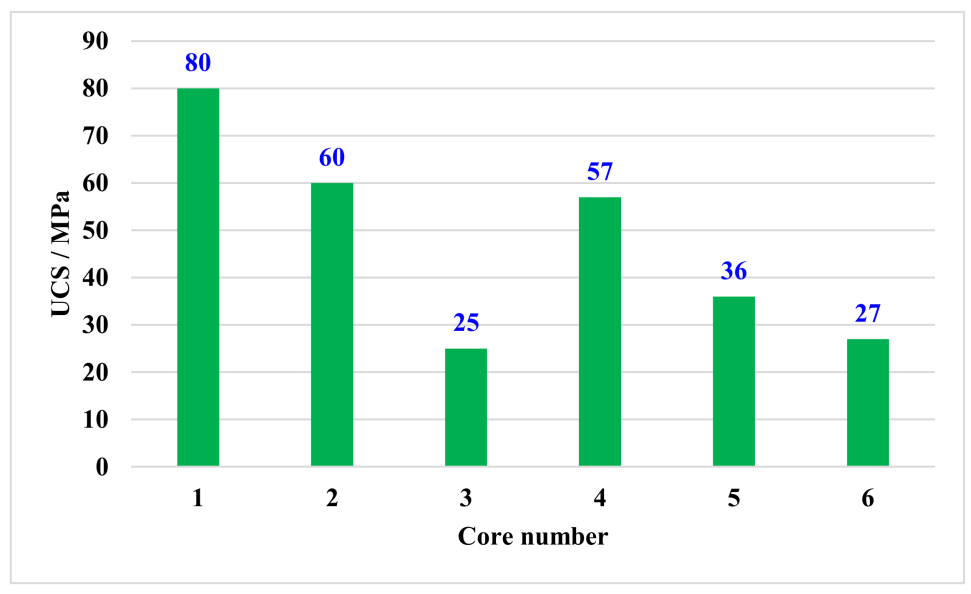

Figure 4. Comparison of carbonate UCS.

Table 1. Summary of carbonate uniaxial and triaxial test data.

\begin{tabular}{cccccc}
\hline Core Number & Density/g.cm $\mathbf{c m}^{-3}$ & $\begin{array}{c}\text { Confining } \\
\text { Pressure/MPa }\end{array}$ & $\begin{array}{c}\text { Compressive } \\
\text { Strength/MPa }\end{array}$ & $\begin{array}{c}\text { Elastic } \\
\text { Modulus/GPa }\end{array}$ & $\begin{array}{c}\text { Poisson's } \\
\text { Ratio }\end{array}$ \\
\hline 1 & 2.65 & 0 & 80 & 18.11 & 0.24 \\
2 & 2.64 & 0 & 60 & 11.89 & 0.21 \\
3 & 2.64 & 0 & 25 & 5.00 & 0.20 \\
4 & 2.57 & 0 & 57 & 17.36 & 0.22 \\
5 & 2.64 & 0 & 36 & 7.85 & 0.21 \\
6 & 2.63 & 0 & 27 & 4.54 & 0.27 \\
\hline 7 & 2.64 & 15 & 183 & 29.15 & 0.29 \\
8 & 2.64 & 15 & 140 & 27.14 & 0.19 \\
9 & 2.65 & 15 & 138 & 20.51 & 0.20 \\
10 & 2.62 & 20 & 170 & 38.49 & 0.31 \\
\hline 11 & 2.64 & 20 & 244 & 26.82 & 0.23 \\
12 & 2.66 & 20 & 184 & 35.03 & 0.21 \\
13 & 2.63 & 20 & 200 & 38.10 & 0.19 \\
14 & 2.63 & 40 & 282 & 39.24 & 0.26 \\
\hline 15 & 2.68 & 40 & 264 & 29.27 & 0.30 \\
16 & 2.65 & 50 & 292 & 35.70 & 0.33 \\
\hline 17 & 2.61 & 50 & 328 & 35.15 & 0.20 \\
\hline
\end{tabular}

\subsection{Experimental Study on Rock Physical and Chemical Properties}

Porosity and permeability are not only basic parameters of rock physical properties but also input parameters in fluid-solid coupling simulation. In this section, the porosity and permeability of the cores from A1-A3 wells in the Tarim Basin were measured by the 112A permeability meter and the UP-300 core porosity meter. It can be found that some cores contain cracks and fissures while the others are intact (Table 2). The methods for porosity and permeability measurement can refer to the reference [27]. The results show that the carbonate matrix is tight, with a porosity of $0.4-2.5 \%$ and a permeability of $0.02-3.15 \mathrm{md}$, which indicates that the reservoir exhibits ultra-low porosity and ultra-low permeability. Meanwhile, some of the carbonate rocks have a dual-porosity structure, and they are rich in cracks and fractures, resulting in permeability which can reach $38.8 \mathrm{md}$. The mineral composition of the cores has been measured by an XRD diffractometer; the results (Table 3 ) show that the content of calcite in the samples is approximately more than $90 \%$, which demonstrates that the carbonate rocks are relatively pure. It can be observed that a large number of low-angle micro-cracks with irregular trends were developed on the surface of the rocks (Figure 5). Meanwhile, flaky illite-smectite mixed layers and micron-scale cracks can be observed inside the core by scanning electron microscope (Figure 6), which is consistent with the conclusions mentioned above. 
Table 2. Summary of carbonate porosity and permeability test data.

\begin{tabular}{|c|c|c|c|c|c|c|}
\hline Well Number & Core Number & Well Depth/m & Density $/ \mathrm{g} \cdot \mathrm{cm}^{-3}$ & Porosity/\% & Permeability/mD & Remarks \\
\hline \multirow{3}{*}{ A1 } & 19 & 7268.1 & 2.69 & 0.6 & 0.46 & contain cracks \\
\hline & 20 & 7274.0 & 2.69 & 1.1 & 6.75 & contain fissures \\
\hline & 21 & 7288.8 & 2.70 & 0.6 & 1.93 & intact \\
\hline \multirow{3}{*}{ A2 } & 22 & 7350.7 & 2.70 & 0.4 & 0.05 & intact \\
\hline & 23 & 7353.6 & 2.71 & 1.9 & 0.03 & intact \\
\hline & 24 & 7356.9 & 2.71 & 2.2 & 0.56 & intact \\
\hline \multirow{3}{*}{ A3 } & 25 & 7358.4 & 2.71 & 1.3 & 0.02 & intact \\
\hline & 26 & 7446.3 & 2.71 & 2.5 & 3.15 & intact \\
\hline & 27 & 7737.4 & 2.70 & 0.9 & 38.8 & contain fissures \\
\hline
\end{tabular}

Table 3. Summary of carbonate mineral composition test data.

\begin{tabular}{ccccccc}
\hline \multirow{2}{*}{$\begin{array}{c}\text { Core Number } \\
\text { Mineral Type }\end{array}$} & Quartz & Plagioclase & Calcite & Dolomite & Anhydrite & Clay \\
\cline { 2 - 6 } & 1.0 & 1.2 & 97.8 & $/$ & $/$ & $/$ \\
28 & 2.6 & 1.3 & 92.3 & 3.8 & $/$ & $/$ \\
30 & 6.2 & 3.1 & 90.7 & $/$ & 7.9 & $/$ \\
31 & 1.6 & $/$ & 89.8 & 7.7 & $/$ \\
\hline
\end{tabular}

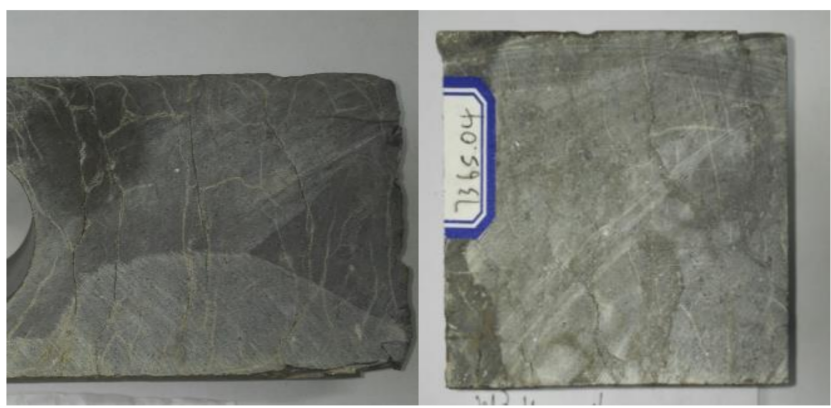

Figure 5. Observation of carbonate block.

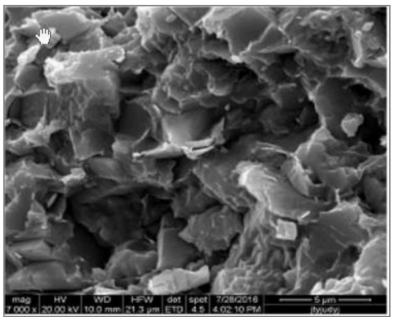

(a)

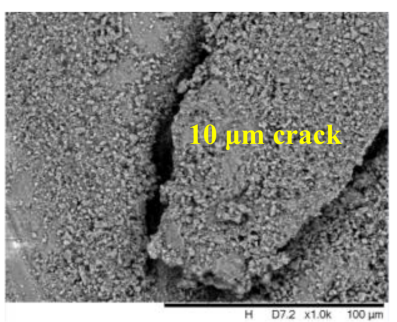

(c)

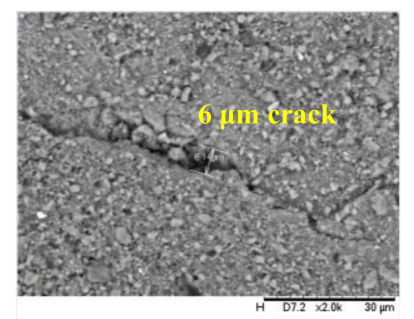

(b)

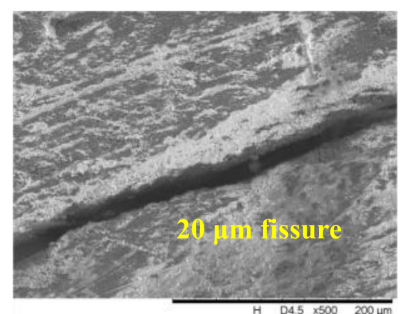

(d)

Figure 6. Scanning electron microscope of carbonate sample ((a) Illite-smectite mixed layers, (b-d) Micron-scale cracks). 
The production of oil and gas is a step after well completion and fracturing, so the formation rocks before production have chemically reacted with the working fluids, such as completion fluid and acid. The chemical properties of the carbonate rocks are relatively active; therefore, they can easily interact with drilling and completion fluids, and mechanical property damages may be caused as a result. Especially for deep carbonate reservoirs, the implementation of acid fracturing is one of the most important means to promote productivity. Therefore, the changes in the properties of rocks caused by acid dissolution cannot be ignored, which has been confirmed by many researchers [28-31]. Working fluids with different components may have diverse effects on the mechanical properties of rocks due to their various chemical properties [32]. Since the main component of the completion fluid in the target block of the Tarim Basin is $\mathrm{CaCl}_{2}$, mechanical tests were carried out by using the core samples treated by gelling acid soaking and saltwater $\left(\mathrm{CaCl}_{2}\right)$ displacing in order to analyze the influence of different working fluids on rock strength. The test results (Figures 7 and 8 ) show that the compressive strength of the cores decreased by $18-33 \%$ and $4-21 \%$ after soaking in acid and displacing $\mathrm{CaCl}_{2}$ saline for 2 $\mathrm{h}$, respectively. The influence degree of the working fluid decreases with the increase of confining pressure. Therefore, the compressive strength of the rocks in the target zone can be decreased by $20 \%$ and $5 \%$ approximately after the reaction with acid and saline, respectively, according to the buried depth of the target block in this study is about $7000 \mathrm{~m}$ and the effective confining pressure exceeds $80 \mathrm{MPa}$ there.

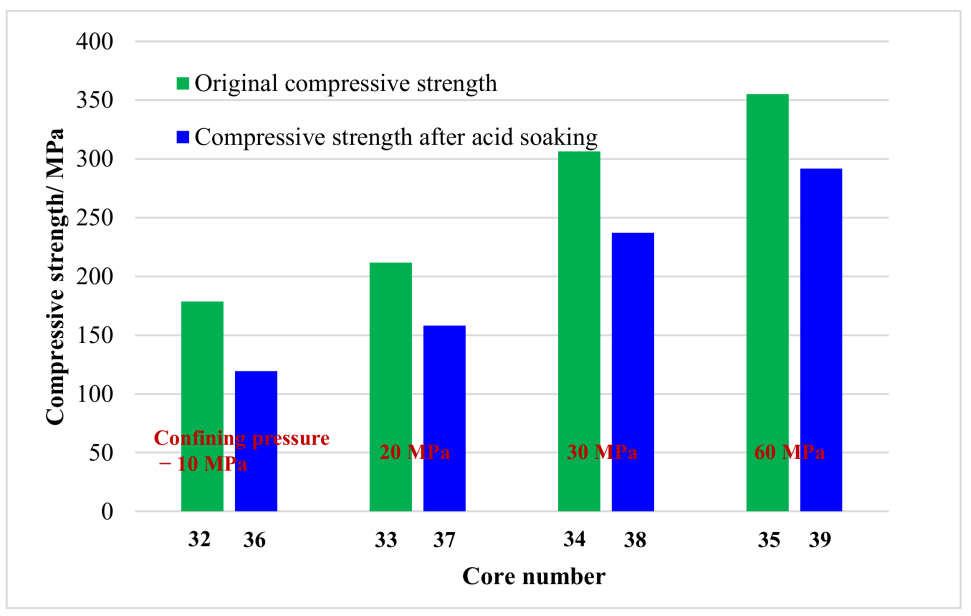

Figure 7. Compressive strength of carbonate cores before and after soaking acid.

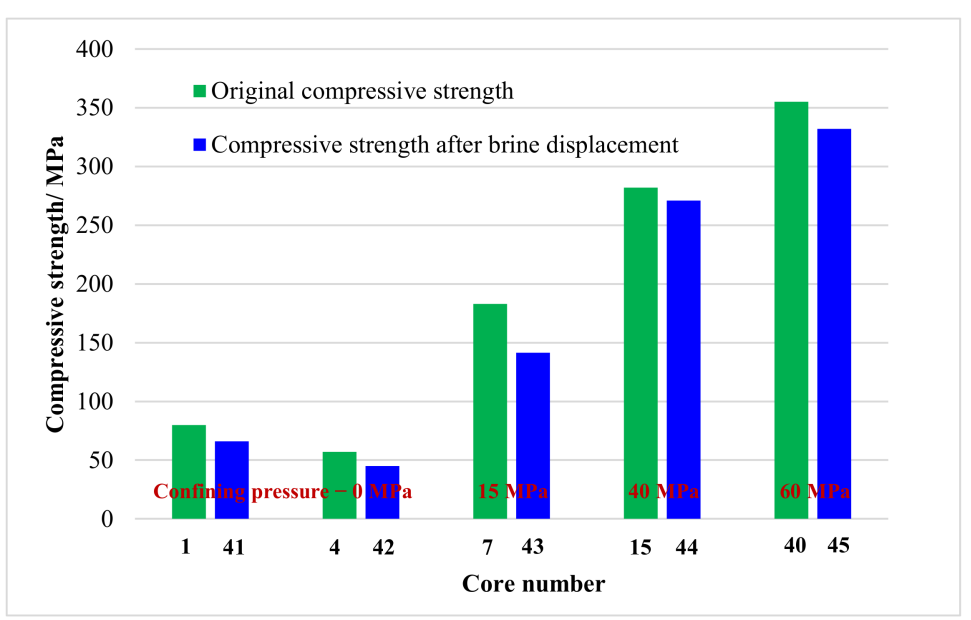

Figure 8. Compressive strength of carbonate cores before and after displacing brine. 


\section{Evaluation Methods for Predicting Production Pressure Differential}

A reasonable pressure differential is an important prerequisite for ensuring safe and efficient production. The productivity cannot be effectively released with a low-pressure differential. On the other side, wellbore instability may be caused if the pressure differential is too high. In particular, some production wells in the Tarim Basin suffer serious tubing blockage problems due to excessively high-pressure differential, as mentioned above. Therefore, a feasible method for evaluating the production pressure differential accurately is much more necessary. In this section, both analytical methods and numerical methods are applied to evaluating the production pressure differential. In fact, operators in oilfields occasionally use the empirical method to directly assess the pressure differential, but this will not be discussed here due to its strong limitations for different blocks.

\subsection{Analytical Method for Production Pressure Differential Evaluation}

Two kinds of sand production mechanisms should be considered when determining the critical production pressure differential of sandstone reservoirs: shear failure caused by excessive in-situ stress difference and particle shedding caused by an excessive fluid pressure gradient. A generally accepted view is that sandstone is not easy to lose stability under a "primitive state". Shear weakening and swelling must have occurred before sandstone particles are carried out by hydrodynamic forces [33]. Therefore, it's not hard to infer that the main cause of wellbore instability in carbonate formation is shear failure rather than particle shedding by analogy to sandstone. Based on this principle, a variety of analytical evaluation methods have been derived.

1. Production pressure differential evaluation based on Mohr-Coulomb criterion

When analyzing the wellbore stability, the wellbore is generally assumed as a middle circular hole in an infinite stratum, which is controlled by the three-dimensional in-situ stress and subjected to plane strain conditions. As mentioned above, the shear failure is caused by excessive in-situ stress difference, and the differential stress on the wellbore reaches its maximum in the direction of the minimum horizontal in-situ stress, where the risk of wellbore instability is the highest. Considering that the carbonate is a porous medium, and assuming that the pores are completely filled with fluid during production, the effective stress distribution on the borehole wall in the direction of the horizontal minimum in-situ stress can be expressed as follows:

$$
\left\{\begin{array}{c}
\sigma^{\prime}{ }_{r}=p_{w}-\alpha p_{p} \\
\sigma^{\prime}{ }_{\theta}=3 \sigma_{H}-\sigma_{h}-p_{w}+\delta\left(p_{w}-p_{p}\right)-\alpha p_{p} \\
\sigma_{z}^{\prime}=\sigma_{v}+2 v\left(\sigma_{H}-\sigma_{h}\right)+\delta\left(p_{w}-p_{p}\right)-\alpha p_{p}
\end{array}\right.
$$

where $\sigma_{r}^{\prime}, \sigma^{\prime}{ }_{\theta}$ and $\sigma_{z}^{\prime}$ are the radial, circumferential and axial effective stress, respectively, MPa. $p_{w}$ is the bottomhole pressure; MPa. $p_{p}$ is the pore pressure, MPa. $\sigma_{H}, \sigma_{h}$ and $\sigma_{v}$ are the horizontal-maximum, horizontal-minimum and vertical in-situ stress, respectively, MPa. $\alpha$ is the effective stress coefficient dimensionless. $v$ is Poisson's ratio, dimensionless. $\delta$ is an intermediate variable expressed as $\delta=\alpha \frac{1-2 v}{1-v}$.

The production pressure differential $\Delta p$ is defined as Equation (3):

$$
\Delta p=p_{p}-p_{w}
$$

Substituting Equation (3) into Equation (2), the effective stress on the borehole wall can be expressed by $\Delta p$ :

$$
\left\{\begin{array}{c}
\sigma_{r}^{\prime}=(1-\alpha) p_{p}-\Delta p \\
\sigma^{\prime}{ }_{\theta}=3 \sigma_{H}-\sigma_{h}+(1-\delta) \Delta p-(1+\alpha) p_{p} \\
\sigma_{z}^{\prime}=\sigma_{v}+2 v\left(\sigma_{H}-\sigma_{h}\right)-\delta \Delta p-\alpha p_{p}
\end{array}\right.
$$

The production pressure differential can be derived by substituting Equation (4) into Equation (1). However, when using the analytical method, the calculation is often 
inconvenient due to the complexity of the solution form. Therefore, the wellbore instability index $\mathrm{S}$ is introduced as follows:

$$
S=\sigma_{3}^{\prime} \cot ^{2}\left(\frac{\pi}{4}-\frac{\varphi}{2}\right)+2 C \cot \left(\frac{\pi}{4}-\frac{\varphi}{2}\right)-\sigma_{1}^{\prime}
$$

When $S>0$, the formation is in a stable state; when $S=0$, the formation is in a critical state; when $S<0$, the formation is in a yielding state.

2. Production pressure differential evaluation based on Drucker-Prager criterion

The Mohr-Coulomb criterion commonly does not take the magnitude of the intermediate principal stress into account, which may result in a smaller designed pressure differential. The effect of the intermediate principal stress cannot be ignored when the rock is under triaxial stress. Therefore, the Drucker-Prager criterion [16] is used as the basis for judging whether the wellbore is stable or not, and its expression is:

$$
S=\lambda I_{1}+K_{f}-\sqrt{J_{2}}
$$

where, $\sigma_{1}, \sigma_{2}$ and $\sigma_{3}$ are the maximum, intermediate and minimum principal stress, respectively. $\sigma_{1}^{\prime}{ }_{1}, \sigma_{2}^{\prime}$ and $\sigma_{3}^{\prime}$ are three effective principal stresses, respectively. $\lambda$ and $K_{f}$ are related parameters of rock mechanics, which can be defined with the Equations (9) and (10), respectively.

$$
\begin{gathered}
I_{1}=\sigma^{\prime}{ }_{1}+\sigma^{\prime}{ }_{2}+\sigma^{\prime}{ }_{3} \\
J_{2}=\frac{1}{6}\left(\left(\sigma_{1}-\sigma_{2}\right)^{2}+\left(\sigma_{2}-\sigma_{3}\right)^{2}+\left(\sigma_{3}-\sigma_{1}\right)^{2}\right) \\
\lambda=\frac{\sqrt{3} \sin \varphi}{3 \sqrt{3+\sin \varphi^{2}}} \\
K_{f}=\frac{\sqrt{3} C \cos \varphi}{\sqrt{3+\sin \varphi^{2}}}
\end{gathered}
$$

3. Production Pressure Differential Evaluation Based on Hoek-Brown Criterion

According to the research of Tan Q et al. [24], the uniaxial and triaxial tests data of the carbonate rocks in the Tarim Basin can be well fitted by the Hoek-Brown criterion [17]. Therefore, the expression of the wellbore instability index can be written as:

$$
S=\sigma_{3}^{\prime}+\sigma_{c i}\left(m_{b} \frac{\sigma_{3}^{\prime}}{\sigma_{c i}}+s\right)^{a}-\sigma_{1}^{\prime}
$$

where $\sigma_{c i}$ is the UCS of intact rock, MPa. GSI is the geological strength index. D is the influence coefficient of rock damage and stress relaxation, with a value range of $0-1 . m_{b}$ and $m_{i}$ are empirical parameters. $\mathrm{D}$ and $\mathrm{s}$ are the constants related to rock mass properties.

$$
\begin{gathered}
m_{b}=m_{i} \exp \left(\frac{G S I-100}{28-14 D}\right) \\
s=\exp \left(\frac{G S I-100}{9-3 D}\right) \\
a=0.5+\frac{1}{6}\left(e^{-G S I / 15}-e^{-20 / 3}\right)
\end{gathered}
$$

4. Production Pressure Differential Evaluation Based on Mogi-Coulomb Criterion

Although the Drucker-Prager criterion can make up for the shortcoming of the MohrCoulomb criterion that does not consider the effect of the intermediate principal stress; however, the effect of the intermediate principal stress is sometimes overestimated by the Drucker-Prager criterion for some types of rocks, leading to an overly optimistic estimate of the production pressure differential and resulting in complex accidents. Therefore, the 
Mogi-Coulomb criterion [19] is introduced to evaluate the wellbore stability, which is between the Drucker-Prager criterion and the Mohr-Coulomb criterion and can account the effect of the intermediate principal stress into account moderately:

$$
S=a_{1}+b_{1} \sigma_{m, 2}^{\prime}-\tau_{o t c}
$$

where $\tau_{o t c}$ is the octahedral shear stress, MPa. $\sigma_{m, 2}^{\prime}$ is the effective mean normal stress, MPa. $a_{1}$ and $b_{1}$ are the Mogi-Coulomb strength parameters.

$$
\begin{gathered}
\tau_{\text {otc }}=\frac{1}{3} \sqrt{\left(\sigma_{1}-\sigma_{2}\right)^{2}+\left(\sigma_{2}-\sigma_{3}\right)^{2}+\left(\sigma_{3}-\sigma_{1}\right)^{2}} \\
\sigma^{\prime}{ }_{m, 2}=\frac{\sigma^{\prime}{ }_{1}+\sigma^{\prime}{ }_{3}}{2} \\
a_{1}=\frac{2 \sqrt{2}}{3} c \cos \varphi \\
b_{1}=\frac{2 \sqrt{2}}{3} \sin \varphi
\end{gathered}
$$

The wellbore instability index established based on different stress failure criteria can be applied in the analysis of the production pressure differential according to the actual engineering conditions. However, the analytical evaluation methods mentioned above are all based on the assumption that the rock is an elastic or elastoplastic material, and it will fall into the failure state when the rock enters into plasticity. However, as mentioned above, the carbonate rocks still have some pressure bearing capacity under a plastic state. Therefore, it is necessary to develop a numerical evaluation method to study the post-peak failure behavior of the carbonate rocks.

\subsection{Numerical Method for Production Pressure Differential Evaluation}

It has been pointed out in Section 2.1 that the carbonate rocks in the Tarim Basin are neither elastic-brittle nor ideal elastic-plastic material. Especially under a certain confining pressure, the carbonate cores have a remarkable residual strength and feature strain-softening after the peak strength, which is concluded by the stress-strain relationship (Figure 9). Furthermore, using numerical simulation to describe the post-peak mechanical behavior and failure characteristics of the rock has been widely accepted and applied. Therefore, the governing equation of strain-softening is used in the numerical simulation, which is expressed as follows:

$$
\begin{gathered}
\varphi=\left\{\begin{array}{cc}
\varphi_{0}-\left(\varphi_{0}-\varphi_{r}\right) \bar{\varepsilon}^{p} / \bar{\varepsilon}_{c r}^{p} & 0<\bar{\varepsilon}^{p}<\bar{\varepsilon}_{c r}^{p} \\
\varphi_{r} & \bar{\varepsilon}^{p} \geq \bar{\varepsilon}_{c r}^{p}
\end{array}\right. \\
c=\left\{\begin{array}{cc}
c_{0}-\left(c_{0}-c_{r}\right) \bar{\varepsilon}^{p} / \bar{\varepsilon}_{c r}^{p} & 0<\bar{\varepsilon}^{p}<\bar{\varepsilon}_{c r}^{p} \\
c_{r} & \bar{\varepsilon}^{p} \geq \bar{\varepsilon}_{c r}^{p}
\end{array}\right.
\end{gathered}
$$

where $\varphi_{0}$ and $\varphi_{r}$ are the initial and the residual internal friction angle, respectively, in ${ }^{\circ}$. $c_{0}$ and $c_{r}$ are the initial and residual cohesion respectively, MPa. $\bar{\varepsilon}_{c r}^{p}$ is the critical plastic strain, marking the beginning of residual deformation. $\bar{\varepsilon}^{p}$ is the equivalent plastic strain, which is defined as:

$$
\bar{\varepsilon}_{p}=\sqrt{\frac{2}{3}\left(\varepsilon_{p 1}^{2}+\varepsilon_{p 2}^{2}+\varepsilon_{p 3}^{2}\right)}
$$

where in, $\varepsilon_{p 1}, \varepsilon_{p 2}$ and $\varepsilon_{p 3}$ are plastic principal strains. 


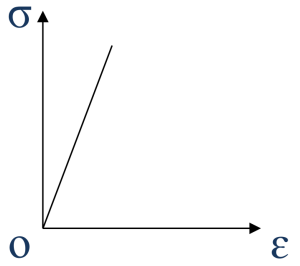

(a)

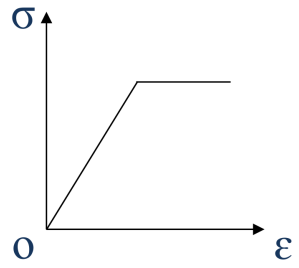

(b)

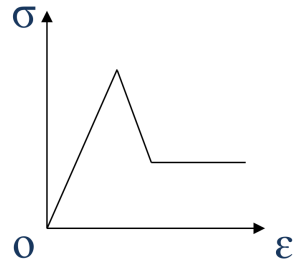

(c)

Figure 9. Typical stress-strain relationship curve ((a) elasticity; (b) ideal elastoplasticity; (c) strain softening).

Equations (20) and (21) adopt a linear softening process, which can reflect the changes of the internal friction angle and cohesion with the increase of equivalent plastic strain. The value of critical equivalent plastic strain needs to be estimated based on the stress-strain curve of the rock triaxial test.

A plane model containing formation and wellbore has been established by ABAQUS finite element program. Due to the symmetry of the wellbore and formation about the $x$ and y axes, only $1 / 4$ of the model was taken into the calculation (indicated by the red frame in Figure 10) to improve the calculation effectiveness. The model considered fluid-solid coupling, and thus, it can realize the coupling calculation of fluid pressure and rock stress changes in the quasi-static production process. For rocks with post-peak strain softening properties, such as coal, Liu W et al. [34] used the user subroutines written by the ABAQUS general program to automatically adjust the calculation time step, which can overcome the problem of numerical non-convergence in the calculation process. In this section, the user subroutines are also applied to ensuring the convergence of the strain-softening calculation.

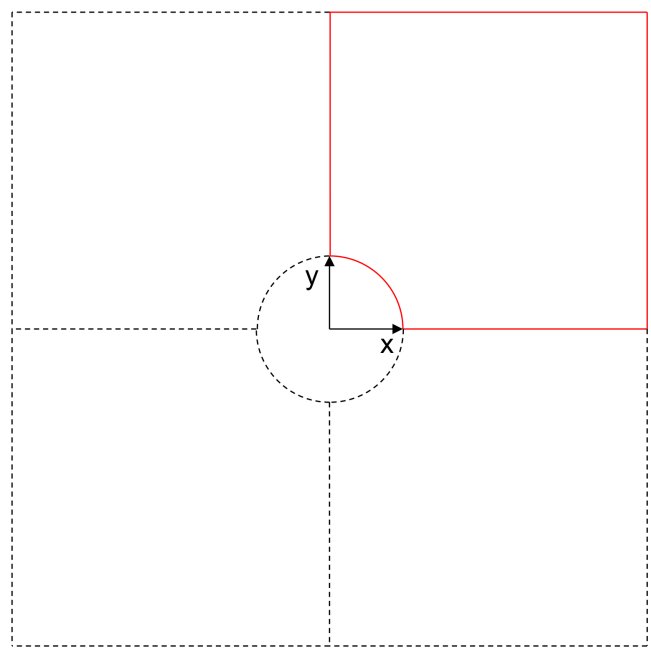

Figure 10. Schematic diagram of $1 / 4$ wellbore-formation model.

Since the calculation is subject to plane strain conditions and fluid-solid coupling, the unit type used is CPE8RP, and the amount of units is about 14,000. The near-wellbore grids have been refined to improve the calculation accuracy (Figure 11). Taking a vertical well as an example, the stress and displacement boundary conditions of the model are shown in Figure 12. Balanced in-situ stress was applied inside the formation. The $x, y$ and $\mathrm{z}$ directions in the model are the directions of minimum horizontal in-situ stress, maximum horizontal in-situ stress and overburden stress, respectively. Pore pressure was applied in the formation, and hydrostatic column pressure was applied inside the wellbore. The left and the lower boundary are symmetrical about the $y$-axis and the $x$-axis, respectively, while the right and the upper boundary were set fixed displacement in the $\mathrm{x}$ - and $\mathrm{y}$-direction, respectively. 


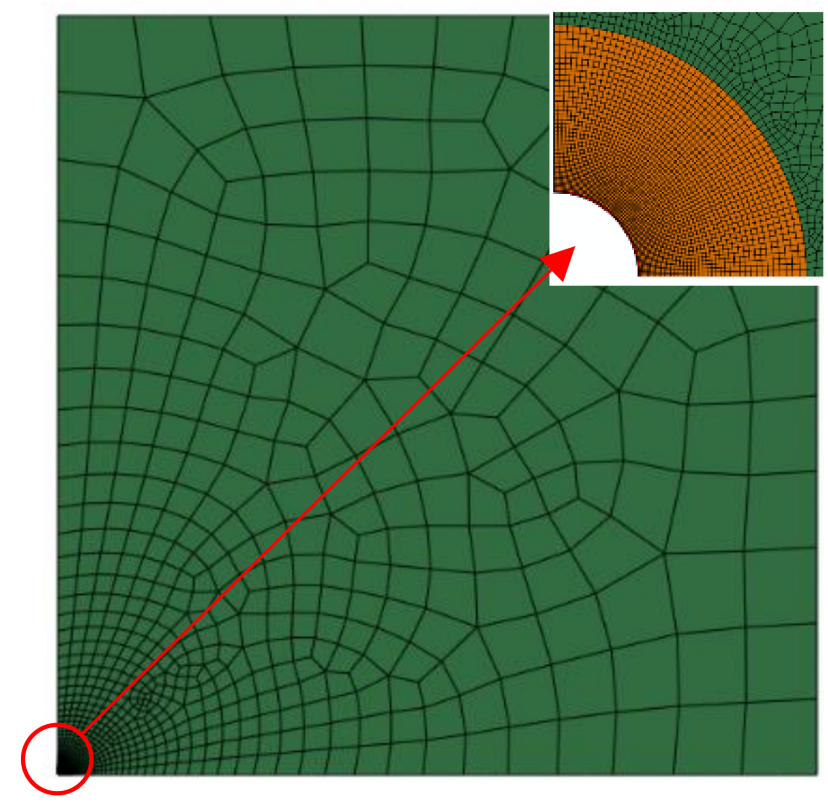

Figure 11. Two-dimensional finite element model and meshing.

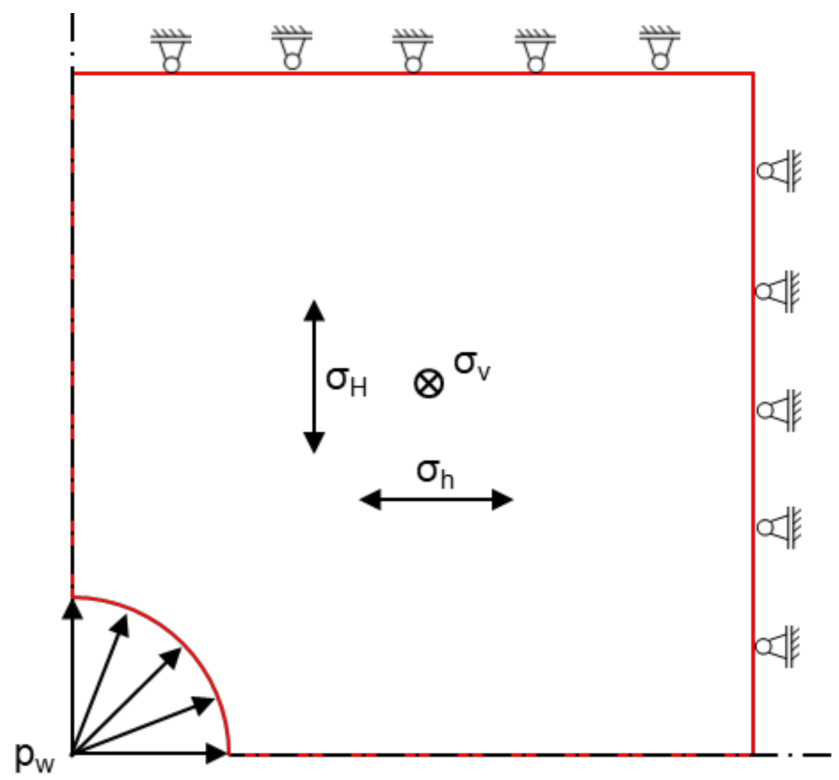

Figure 12. Schematic diagram of the boundary conditions.

So far, the numerical model can simulate the expansion and connectivity of the near-wellbore plastic zone under different in-situ stress levels and pressure differential conditions. It can further judge whether the wellbore is stable or not according to the development of the plastic zone in order to determine a reasonable production pressure differential.

\section{Application and Discussion}

Analytical and numerical methods were both used to evaluate the production pressure differential of horizontal wells by using the geological conditions (Table 4) of the carbonate reservoirs in the Tarim Basin. It can be found that the target block is controlled by the strike-slip stress regime, which is associated with $\sigma_{H} \geq \sigma_{V} \geq \sigma_{h}$. Therefore, the critical production pressure differential in the direction of horizontal minimum in-situ stress is most practical because horizontal wells drilled in that direction have the lowest risk of wellbore instability [35-37]. 
Table 4. Calculation parameters of the production pressure differential evaluation.

\begin{tabular}{cc}
\hline Geological Parameters & Value Assignment \\
\hline Vertical depth/m & 7510 \\
Overburden pressure/MPa & 179.5 \\
Maximum horizontal in-situ stress $/ \mathrm{MPa}$ & 182.5 \\
Minimum horizontal in-situ stress $/ \mathrm{MPa}$ & 135.2 \\
Pore pressure/MPa & 82.6 \\
Effective stress coefficient & 0.6 \\
Porosity/\% & 2 \\
Permeability/mD & 10 \\
Elastic Modulus/GPa & 17 \\
Poisson's ratio & 0.23 \\
Cohesion/MPa & 13.4 \\
Residual cohesion/MPa & 11.2 \\
Internal friction angle $/^{\circ}$ & 42 \\
Residual internal friction angle $/{ }^{\circ}$ & 38 \\
Critical equivalent plastic strain & 0.018 \\
\hline
\end{tabular}

When using analytical methods with different failure criteria mentioned above, the production pressure differential is $0,25.8,9.8$ and $10.7 \mathrm{MPa}$, respectively (Figure 13). The production differential is 0 with Mohr-Coulomb criterion, which means it is impossible to produce without an accident. This is obviously inconsistent with the actual production. Besides, the accuracy of the Drucker-Prager, Hoek-Brown and Mogi-Coulomb criteria will be discussed below combined with the field data.

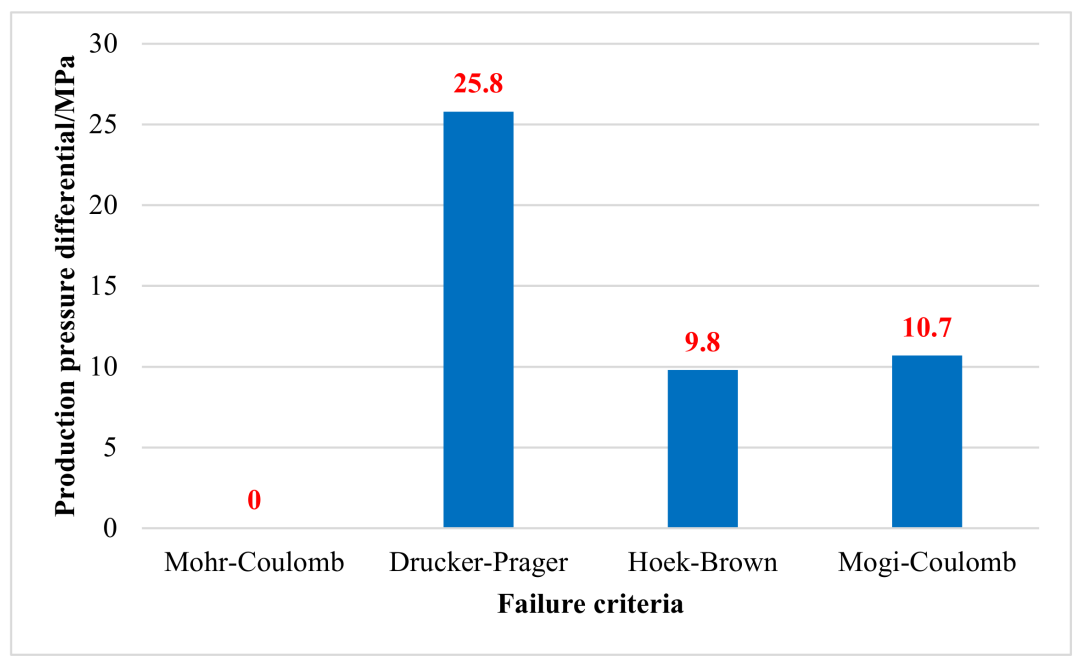

Figure 13. Comparison of production pressure differential evaluated by analytical methods.

The plastic deformation and failure of the near-wellbore formation were simulated with the pressure differential of 10-40 MPa by using the numerical model previously established. It can be found in Figure 14 that the plastic zone does not expand uniformly due to the influence of strain softening, and the rocks on the borehole wall will continue to expand deeply into the formation after it begins to enter into plasticity. A "V-shaped" area will form when two adjacent plastic zones are connected to each other, in which the enveloped rock may peel off and fall down. As a result, wellbore plugging may occur. However, the collapse is along multiple directions around the wellbore instead of a single direction due to the small difference between the overburden pressure and the maximum horizontal in-situ stress. There are 6 "V-shaped" areas formed around the wellbore when the production pressure differential is $40 \mathrm{MPa}$, as shown in Figure 14, and the expansion of borehole diameter tends to be more uniform. 

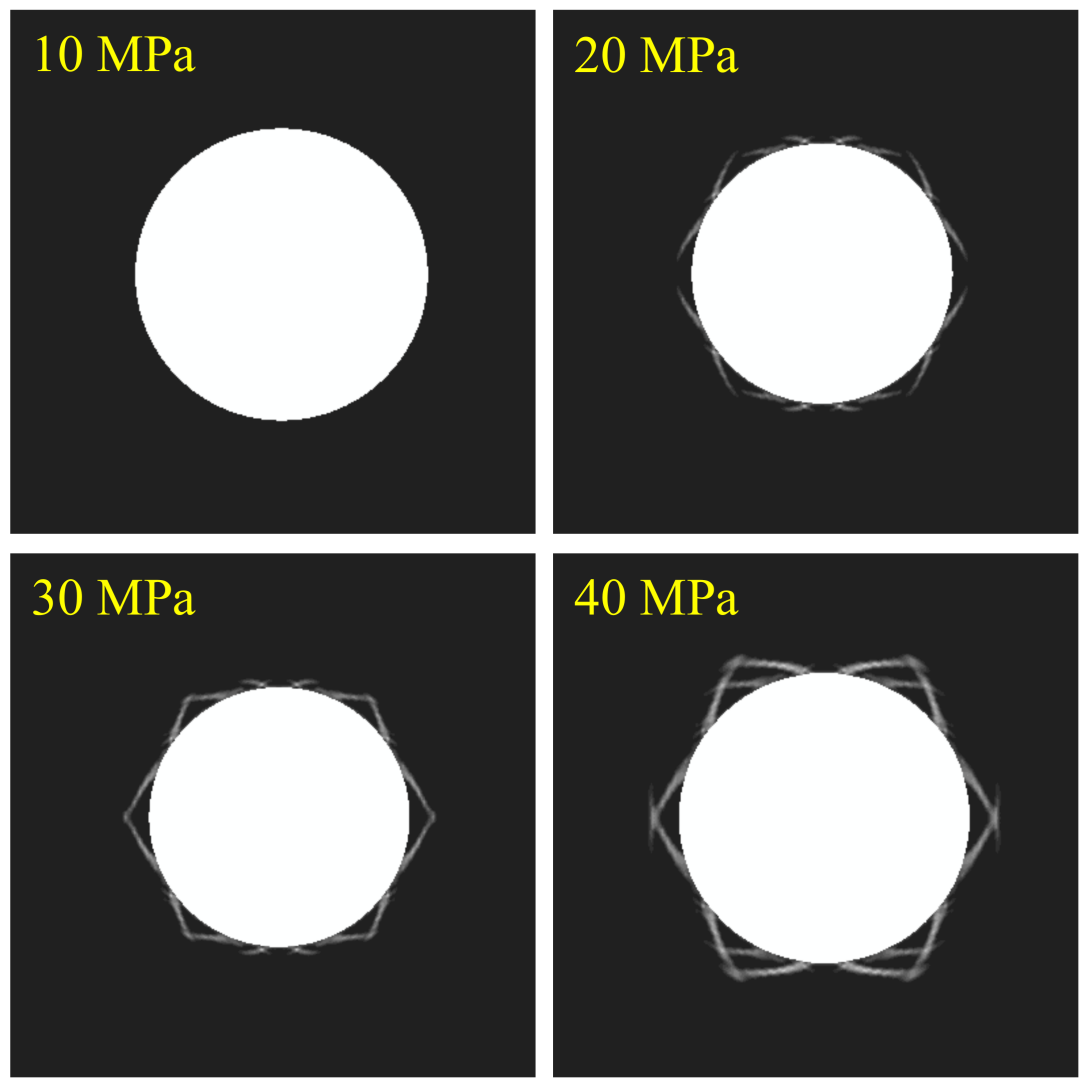

Figure 14. Near-wellbore plastic zone of horizontal wells (drilled in the direction of minimum horizontal in-situ stress) under different production pressure differentials.

In order to perfect the development law of the plastic zone, the production pressure differential analysis of vertical wells with the pressure differential of 10-40 MPa was also carried out (Figure 15). However, the wellbore collapse occurred only in the direction of the minimum horizontal in-situ stress due to the large difference between the two horizontal in-situ stresses, and the plastic zone finally connected into an ellipse with the increase of the pressure differential, which has been confirmed by many studies [38-40]. Therefore, it can be concluded that the mechanism of wellbore instability in this strain-softening formation is the interconnection of plastic zones. As shown in Figure 14, the formation has almost no plastic zone under the pressure differential of $10 \mathrm{MPa}$, while the near-wellbore plastic zone expands and connects rapidly under the pressure differential of $20 \mathrm{MPa}$, which is a precursor of wellbore instability. Therefore, the critical production pressure differential is controlled within the range of $10-20 \mathrm{MPa}$. Furthermore, by analyzing the gradual expansion scale of the plastic zone under the pressure differential of 10-20 MPa (Figure 16), it can be found that the critical value of the production pressure differential is $16-18 \mathrm{MPa}$ when the near-wellbore plastic zones are about to connect with each other. 

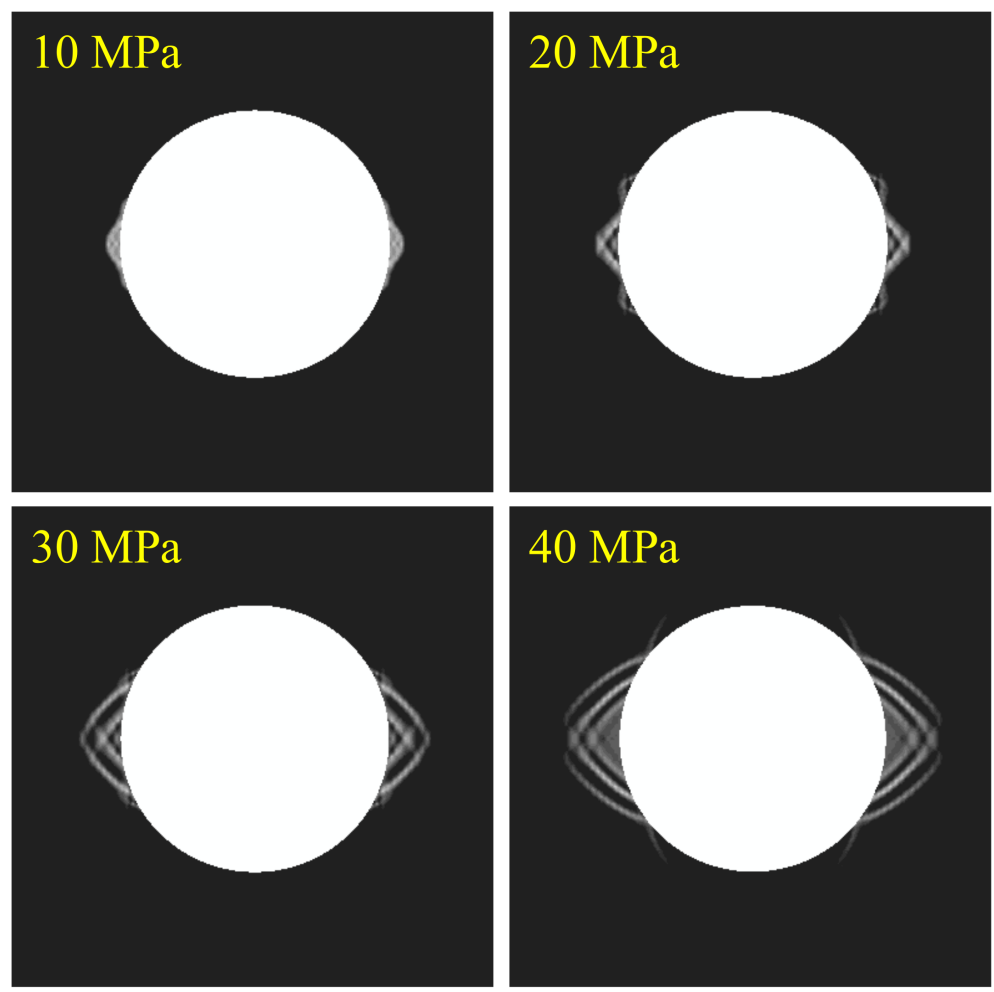

Figure 15. Near-wellbore plastic zone of vertical wells under different production pressure differentials.
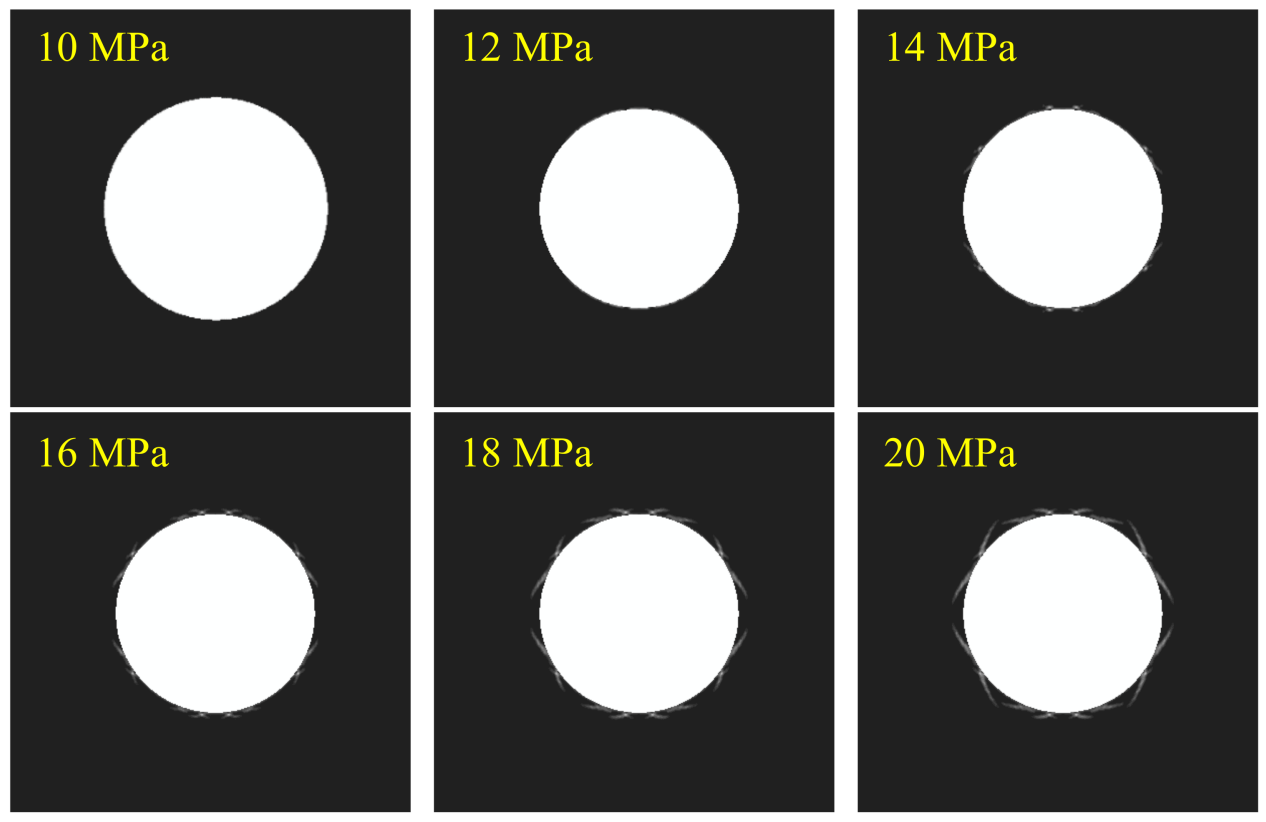

Figure 16. Simulation of the expansion pattern and connectivity trend of the near-wellbore plastic zone.

Table 5 presents the summary of production data in the carbonate reservoirs of the Tarim Basin. The summary indicates that the degree of tubing blockage is different under different pressure differentials, and it gets more severe with the increase of the production pressure differential. No blockage happened when the production pressure differential is $15 \mathrm{MPa}$, while the oil pipe was severely blocked under the pressure differential of 30-40 MPa. The most commonly used production pressure differential is $15-16 \mathrm{MPa}$ through a careful investigation. Furthermore, by combining the above evaluation results of analytical and numerical methods, the following points can be drawn: 
(1) The Mohr-Coulomb criterion is too conservative in the estimation of rock failure. Although it has many successful applications in wellbore stability analysis, it is obviously not suitable for production pressure differential analysis under quasistatic conditions because there are no dynamic effects, such as drill string vibration and pressure fluctuating, during the production process. In contrast, the production pressure differential evaluated by the Drucker-Prager criterion is too optimistic. There is a strong risk of blockage when the production pressure differential is above $20 \mathrm{MPa}$ according to the production practice, so the results evaluated by the Drucker-Prager criterion cannot be adopted too.

(2) The pressure differential evaluation results obtained from the Hoek-Brown and MogiCoulomb criteria are close, and neither will cause wellbore instability. Both of them can be used to quickly predict the production pressure differential. However, it should be noted that the selection of the empirical parameters in the Hoek-Brown criterion is experience-dependent. Therefore, a large amount of experimental data and geological data is required for parameter correction, which limits the application of the Hoek-Brown criterion. Meanwhile, the Mogi-Coulomb criterion seems to still underestimate the supporting effect of the intermediate principal stress on the rocks according to the production data, resulting in a slightly lower evaluated production pressure differential and difficulty maximizing the productivity.

(3) The numerical method overcomes the shortcoming of elastic assumption in analytical methods by adding the strain-softening characteristic to the rock material in the finite element model, which helps to reveal the mechanism of wellbore instability and tubing blockage. In addition, the absolute error of the numerical method is less than $3 \mathrm{MPa}$, while that of the analytical methods is more than $4.3 \mathrm{MPa}$. Therefore, the numerical simulation is a better way to determine the critical production pressure differential because it can obtain a more accurate solution. However, solving an analytical formula may only spend a few seconds on the calculator, while the numerical simulation can take tens of minutes or even hours, depending on the computing power of the computer. It cannot be ignored that the numerical method is not as time-efficient as the analytical methods in field applications.

Table 5. Summary of production data in the carbonate reservoirs of the Tarim Basin.

\begin{tabular}{cc}
\hline Production Pressure Differential/MPa & Blockage of Tubing \\
\hline$<15$ & No blockage \\
$15-20$ & Slight blockage \\
$20-30$ & Remarkable blockage \\
$30-40$ & Severe blockage \\
\hline
\end{tabular}

\section{Conclusions}

In order to solve the problem of tubing blockage of the wells in the carbonate reservoirs of the Tarim Basin, a large number of laboratory experiments were carried out to analyze the mechanical, physical and chemical properties of the carbonate rocks. In addition, both analytical and numerical methods were applied to predicting the critical production pressure differential, and the evaluation results were compared with the production data. Finally, the following conclusions can be drawn according to the results of experiments and analysis:

(1) The carbonate rocks in the Tarim Basin feature strong heterogeneity that their porosity is about $0.4-2.5 \%$, permeability is about $0.02-3.15 \mathrm{md}$, uniaxial compressive strength is about $25-80 \mathrm{MPa}$, the elastic modulus is about 10-20 GPa, Poisson's ratio is about $0.19-0.27$, cohesion is about $11-17 \mathrm{MPa}$, and internal friction angle is about $42-46^{\circ}$. Furthermore, the compressive strength can be weakened about $20 \%$ and $5 \%$ after the reaction with gelling acid and completion fluids, respectively. 
(2) The analytical methods can be used to quickly and easily evaluate the production pressure differential, but based on different failure criteria, each method has its own limitation. The method with Mogi-Coulomb criterion can obtain a relatively accurate result according to the comprehensive comparison.

(3) A numerical method based on the finite element model was developed to evaluate the production pressure differential, which can truly reflect the mechanical properties, such as strain-softening of carbonate rocks. Moreover, the simulation revealed the mechanism of wellbore instability that is the rock stripping caused by the interconnection of near-wellbore plastic zones. Above all, the production pressure differential derived from the simulation is most consistent with the production data, which proves that the numerical method mentioned above is the most accurate approach to determine the critical production pressure differential. Therefore, the finite element model proposed in this paper is a better choice for predicting the production pressure differential in deep carbonate reservoirs.

Author Contributions: Conceptualization, J.D. and Q.T.; methodology, W.L.; software, H.W. and W.L.; data curation, Q.T.; writing-original draft preparation, H.W.; writing-review and editing, C.Z. and Z.C. All authors have read and agreed to the published version of the manuscript.

Funding: This research received no external funding.

Conflicts of Interest: The authors declare no conflict of interest.

\section{References}

1. Zhao, W.Z.; Hu, S.Y.; Liu, W.; Wang, T.S.; Li, Y.X. Petroleum geological features and exploration prospect of deep marine carbonate rocks in China onshore: A further discussion. Nat. Gas Ind. B 2014, 1, 11-18.

2. Zeng, Y.J. Key technologies for safe and efficient drilling of marine carbonate ultra-deep oil and gas wells. Pet. Drill. Tech. 2019, 47, 25-33. (In Chinese)

3. Li, Y.; Kang, Z.J.; Xue, Z.J.; Zheng, S.Q. Theories and practices of carbonate reservoirs development in China. Pet. Explor. Dev. 2018, 45, 712-722. [CrossRef]

4. Zhao, W.Z.; Shen, A.J.; Hu, S.Y.; Zhang, B.M.; Pan, W.Q.; Zhou, J.G.; Wang, Z.C. Geological conditions and distributional features of large-scale carbonate reservoirs onshore China. Pet. Explor. Dev. 2012, 39, 1-14. [CrossRef]

5. Chang, C.D.; Zoback, M.D.; Khaksar, A. Empirical relations between rock strength and physical properties in sedimentary rocks. J. Pet. Sci. Eng. 2006, 51, 223-237. [CrossRef]

6. Geertsma, J. Some rock-mechanical aspects of oil and gas well completions. Soc. Pet. Eng. J. 1985, 25, 848-856. [CrossRef]

7. Wang, Y. The effect of a nonlinear Mohr-Coulomb criterion on the stresses and plastic deformation near a circular opening in a poorly consolidated permeable medium. Int. J. Rock Mech. Min. Sci. Geomech. Abstr. 1996, 33, 197-203. [CrossRef]

8. Wang, Y.; Lu, B. A coupled reservoir-geomechanics model and applications to wellbore stability and sand prediction. In Proceedings of the SPE International Thermal Operations and Heavy Oil Symposium, Margarita, Venezuela, 12-14 March 2001; Society of Petroleum Engineers: Richardson, TX, USA, 2001.

9. Yi, X.J. Numerical and Analytical Modeling of Sanding Onset Prediction. Ph.D. Thesis, Texas A\&M University, College Station, TX, USA, August 2003.

10. Liu, X.J.; Liu, H.; Duan, Y.G.; Luo, P.Y.; Wu, X.L. Influence of well completion way on critical producing pressure differential and well productivity in sandstone reservoir. Drill. Prod. Technol. 2007, 30, 33-35. (In Chinese)

11. Wang, A.P. Research on the Stress Distribution and Sanding Prediction Model for Horizontal Wells. Master's Thesis, China University of Petroleum, Beijing, China, April 2011. (In Chinese)

12. Zhang, R.; Shi, X.Y.; Zhu, R.F.; Zhang, C.; Fang, M.Z.; Bo, K.H.; Feng, J.X. Critical drawdown pressure of sanding onset for offshore depleted and water cut gas reservoirs: Modeling and application. J. Nat. Gas Sci. Eng. 2016, 34, 159-169. [CrossRef]

13. Geng, S.H. Experiment Research on Rock Mechanics and Determination of Reasonable Production Pressure Difference-A Case of W Block. Master's Thesis, Yangtze University, Jingzhou, Hubei Province, China, April 2019. (In Chinese)

14. Shi, X.Y.; Huang, X.; Shi, J.Y.; Zhao, G.Y.; Xu, L.Y. Critical drawdown pressure of sanding onset for unconsolidated sandstone reservoirs when reservoir pressure depleted. J. Southwest Pet. Univ. 2020, 42, 115-122. (In Chinese)

15. Jaeger, J.C.; Cook, N.G.W. Fundamentals of Rock Mechanics, 3rd ed.; Chapman and Hall: London, UK, 1979; 593p.

16. Drucker, D.; Prager, W. Soil mechanic sand plastic analysis or limit design. Appl. Math. 1952, 10, 157-165.

17. Hoek, E.; Brown, E.T. The Hoek-Brown failure criterion and GSI-2018 edition. J. Rock Mech. Geotech. Eng. 2019, 11, 445-463. [CrossRef]

18. Zervos, A.; Papanastasiou, P.; Cook, J. Elastoplastic finite element analysis of inclined wellbores. In Proceedings of the SPE/ISRM Rock Mechanics in Petroleum Engineering, Trondheim, Norway, 8-10 July 1998; Society of Petroleum Engineers: Richardson, TX, USA, 1998. 
19. Al-Ajmi, A.M.; Zimmerman, R.W. Relationship between the parameters of the Mogi and Coulomb failure criterion. Int. J. Rock Mech. Min. Sci. 2005, 42, 431-439. [CrossRef]

20. Liu, G.; Cai, M.; Huang, M. Mechanical properties of brittle rock governed by micro-geometric heterogeneity. Comput. Geotech. 2018, 104, 358-372. [CrossRef]

21. Wong, T.F.; Robina, H.C.; Wong, K.T.; Tang, C.A. Microcrack statistics, Weibull distribution and micromechanical modeling of compressive failure in rock. Mech. Mater. 2006, 38, 664-681. [CrossRef]

22. Liu, H.B.; Cui, S.; Meng, Y.F.; Deng, H.; Han, X. Micro-mechanical structure and mechanical properties of fractured carbonate rock. Spec. Oil Gas Reserv. 2020, 27, 155-161. (In Chinese)

23. Xu, K. Characteristics and Main Controlling Factors of Ordovician Carbonate Rock Reservoir in Tazhong Area of Tarim Basin Ph.D. Thesis, China University of Geosciences, Beijing, China, October 2015. (In Chinese)

24. Tan, Q.; Li, S.G.; Su, P.; Weng, H.Y.; Xiao, Y. A classification and description method for carbonate reservoir mechanical properties based on the Hoek-brown criterion. In Proceedings of the 53rd US Rock Mechanics/Geomechanics Symposium, New York, NY, USA, 23-26 June 2019; American Rock Mechanics Association: Alexandria, VA, USA, 2019.

25. Lei, Z.D.; Tao, L.; Zhu, H.Y.; Chen, S.; Liu, Q.Y. Experimental study of Wufeng-Longmaxi shale core: The fracture characteristics and the change of permeability under the natural fractures influence. In Proceedings of the SPE Asia Pacific Hydraulic Fracturing Conference, Beijing, China, 24-26 August 2016; Society of Petroleum Engineers: Richardson, TX, USA, 2016.

26. Fairhurst, C.E.; Hudson, J.A. Draft ISRM suggested method for the complete stress-strain curve for intact rock in uniaxial compression. Int. J. Rock Mech. Min. Sci. 1999, 36, 279-289.

27. Shi, B.Q. Rock Petrophysics Experiment in Medium-Deep Gas Reservoirs. Master's Thesis, China University of Petroleum, Shandong, China, April 2007. (In Chinese)

28. Zhang, R.X.; Hou, B.; Zhou, B.C.; Liu, Y.J.; Xiao, Y.; Zhang, K.P. Effect of acid fracturing on carbonate formation in southwest China based on experimental investigations. J. Nat. Gas Sci. Eng. 2020, 73, 103057. [CrossRef]

29. Hou, B.; Zhang, R.X.; Chen, M.; Kao, J.W.; Liu, X. Investigation on acid fracturing treatment in limestone formation based on true tri-axial experiment. Fuel 2019, 235, 473-484. [CrossRef]

30. Zhang, H.; Zhong, Y.; Zhang, J.; Zhang, Y.C.; Kuang, J.C.; Yang, B. Experimental research on deterioration of mechanical properties of carbonate rocks under acidified conditions. J. Pet. Sci. Eng. 2020, 185, 106612. [CrossRef]

31. Nasr-El-Din, H.A.; Al-Driweesh, S.M.; Metcalf, A.S.; Chesson, J.B. Fracture acidizing: What role does formation softening play in production response? SPE Prod. Oper. 2008, 23, 184-191. [CrossRef]

32. Ru, Z.X.; Zhao, R.; Zhang, J.B.; Deng, S.; Li, H.L.; Wang, Q. Impacts of working fluid immersion on strength of deep-buried rocks in Shunbei, Tarim. Rock Soil Mech. 2020, 41, 1-10. (In Chinese)

33. Zhang, L.W.; Dusseault, M.B. Sand-production simulation in heavy-oil reservoirs. SPE Reserv. Eval. Eng. 2004, 7, 399-407. [CrossRef]

34. Liu, W.; Tan, Q.; Yu, B.H.; Deng, J.G. Modeling the borehole breakout in coal seams with a coupled hydro-mechanical model. In Proceedings of the 51st US Rock Mechanics/Geomechanics Symposium, San Francisco, CA, USA, 25-28 June 2017; American Rock Mechanics Association: Alexandria, VA, USA, 2017.

35. Zhou, S.H.; Hillis, R.; Sandiford, M. On the mechanical stability of inclined wellbores. SPE Drill. Complet. 1996, 11, 67-73. [CrossRef]

36. Kaarstad, E.; Aadnoy, B.S. Optimization of borehole stability using 3-D stress optimization. In Proceedings of the SPE Annual Technical Conference and Exhibition, Dallas, TX, USA, 9-12 October 2005; Society of Petroleum Engineers: Richardson, TX, USA, 2005.

37. Al-Ajmi, A.M.; Zimmerman, R.W. Stability analysis of deviated boreholes using the Mogi-Coulomb failure criterion, with applications to some oil and gas reservoirs. In Proceedings of the IADC/SPE Asia Pacific Drilling Technology Conference 2006-Meeting the Value Challenge: Performance, Deliverability and Cost, Bangkok, Thailand, 13-15 November 2006; IADC/SPE Asia Pacific Drilling Technology Conference and Exhibition: Richardson, TX, USA, 2006.

38. Kanfar, M.F.; Chen, Z.; Rahman, S.S. Effect of material anisotropy on time-dependent wellbore stability. Int. J. Rock Mech. Min. Sci. 2015, 78, 36-45. [CrossRef]

39. Li, Q.; Tang, Z.Q. Optimization of wellbore trajectory using the initial collapse volume. J. Nat. Gas Sci. Eng. 2016, 29, 80-88. [CrossRef]

40. Fan, X.; Zhang, M.M.; Zhang, Q.G.; Zhao, P.F.; Yao, B.W.; Lv, D. Wellbore stability and failure regions analysis of shale formation accounting for weak bedding planes in ordos basin. J. Nat. Gas Sci. Eng. 2020, 77, 103258. [CrossRef] 